\title{
Improvement in Socio-Economic Productivity of HIV Positive Individuals on Antiretroviral Treatment in a Private Setting in South India
}

\author{
Fehmida Visnegarwala, Glory Alexander, Ram Babu \\ ASHA Foundation, Bangalore, India \\ Email: ashafblr@yahoo.co.in
}

How to cite this paper: Visnegarwala, F., Alexander, G. and Babu, R. (2019) Improvement in Socio-Economic Productivity of HIV Positive Individuals on Antiretroviral Treatment in a Private Setting in South India. World Journal of AIDS, 9 , 23-32.

https://doi.org/10.4236/wja.2019.91003

Received: November 30, 2018

Accepted: March 4, 2019

Published: March 7, 2019

Copyright $\odot 2019$ by author(s) and Scientific Research Publishing Inc. This work is licensed under the Creative Commons Attribution International License (CC BY 4.0).

http://creativecommons.org/licenses/by/4.0/

c) (i) Open Access

\begin{abstract}
PLHIV have decreased economic productivity both due to direct and indirect causes. Data from developed countries have shown that at the societal level, high costs ART are offset by increased productivity. We hypothesized that post-ART the SES would improve regardless of the baseline SES and will be sustained over time. Our objective was to perform a comprehensive SES evaluation pre/post ART initiation using an ambispective cohort study design. We used Indian household-specific SES validated tool, with score of $<15$ being indigent to $>76$ being affluent, along with clinical, ART adherence data at median of 6 and 18 months post ART, and compared using paired t-tests. Among 140 persons started on ART, with a median follow up of 22 months, 118 had Pre-ART SES data, of these: 57\% were women; median age was 38 years; $67 \%$ were married; 89 (78\%) had heterosexual sex as HIV risk; 40 (34\%) had major OI and/or TB at presentation. Reported self-occupation was: skilled labourers 41 (35\%); 12 (10\%) unskilled labourers; 27 (23\%) housewives; 26 (22\%) professionals/blue collar job; 1 student, 10 unemployed. The median pre-post ART CD4 cell counts were: 187 and 454 cells/cumm $(\mathrm{P}<$ 0.01); median body weight pre-post ART was 54 and $57 \mathrm{~kg}(\mathrm{P}<0.01) ; 97 \%$ of the participants were $100 \%$ adherent. The mean Pre-ART total SES score was $37.06(+/-10.2)$; and Post-ART SES score $40.62(+10.1 \mathrm{P}<0.001)$ and these results were sustained over time and remained significant even when only monthly income was considered. Our data show a significant impact of ART on SES in a sustained manner in a developing world setting, which has policy level implications.
\end{abstract}

\section{Keywords}

Persons Living with HIV (PLHIV) Anti Retroviral Treatment (ART), Socio-Economic Status (SES) 


\section{Introduction}

The HIV (Human Immunodeficiency Virus) pandemic has affected 36.7 million persons around the world of which 19.5 million people are on treatment with antiviral drugs [1]. The pandemic has taken substantial toll on the "human capital" thus impeding the economic growth of households, communities, societies and nations on the whole [2] [3]. The persons living with HIV have impact on their productivity, not only due to inability to work, but also due to resources required for medical care, and time and resources of the caregivers. HIV/AIDS (Acquired Immune Deficiency Syndrome) leads to impoverishment due to both direct and indirect costs of illness. Direct costs are incurred for the health care access, treatment, transportation etc., while indirect costs constitute loss of productivity of the sick and the healthy care givers, as well as permanent loss of employment, and sale of assets [3] [4] [5].

In many sub-Saharan countries there is a reduction in skilled labor, being replaced by younger, less trained work force, thereby leading to reduced productivity. Thus AIDS seriously weakens the taxable population, and slows growth of the economy [6] [7] [8]. But unlike African countries, the macroeconomic impact of HIV/AIDS is not reflected in the national statistics of South East Asian Countries such as India, which is the third highest country in the world with regard to HIV positive population. Thus the maximum socioeconomic impact due to HIV/AIDS is felt only at the household levels, and rarely at community level. The burden of healthcare, and decreased productivity have been compounded many times over by the stigma and discrimination among adults and children [9]. In countries such as India, an illness such as HIV/AIDS can be catastrophic to the families and push them to poverty and also adversely impact adherence to ART (Anti-Retroviral Treatment) [10] [11].

Since advent of ART there has been a substantial decrease in morbidity and mortality due to HIV/AIDS related illness [12]. This has translated into substantial cost-effectiveness at the societal level, by decreasing the health-care dollars saved per quality year life saved [13] [14]. This has been realized predominantly in decrease in the utilization of overall health care services. There have been many studies which have documented these savings in developed and African countries [7] [10] [11] [15] [16] [17]. Even though ART availability has increased in India, evidence on economic impact on households can be useful for the ability to respond to the epidemic and policy making. However, data on impact of ART on productivity of households of PLHIV (Persons living with HIV) in India are limited [18] [19]. So far there is only one large study which has documented increase in productivity in the Indian setting [18] [19]. There was significant improvement as measured by percentage and number of hours worked, as well as income. However, these data are from a public health setting where the PLHIV are mostly from poor, to lower middle class [19]. Moreover, in that study, the impact of nutritional supplements and household visits could not be differentiated from the impact of ART alone. There are no data on the effec- 
tiveness of ART on productivity in a private setting with a range of patients from various SES (Socio-Economic Status) classes. Moreover, there was no assessment of other fixed assets which can contribute to substantial distribution of wealth.

Thus we sought to evaluate the effect of ART on an urban sample of Indian households, with particular emphasis on individual and household productivity, acquisition of fixed and liquid assets, and overall socioeconomic status using a comprehensive assessment questionnaire with the following hypotheses. ART institution will lead to increased productivity of PLHIV directly and indirectly as evidenced by increase in household income and/or acquisition of assets, and this change in productivity will be evidenced across all households of PLHIV regardless of the baseline SES and will be sustained over time, and the change in productivity will also correlate to adherence to ART, and clinical indicators.

\section{Materials and Methods}

This study was conducted at ASHA (Action, Service, and Hope for AIDS) Foundation, a non-governmental organization (NGO) in Bangalore established since 1998 and working in the field of HIV/AIDS and providing ART for HIV positive patients. Since 2007, ASHA Foundation, has implemented a comprehensive socio-economic status assessment questionnaire for evaluation of free-ART eligibility. This is a well-validated tool to assess SES in the Indian setting [20]. The highest score attainable is 100 and lowest score is 5. The social status is then divided into 6 strata based on total score as lower, middle and upper class. This tool was filled by trained social-workers during a face-to-face interview with the patients, before ART initiation at ASHA foundation. This data was used retrospectively, and prospective data from the SES tool was collected as described below.

All consecutive adults (age $>18$ years) who have enrolled at ASHA Foundation and had had a SES assessment before ART initiation and have had at least six months of active follow up on ART and were still available for face-to-face interview were recruited for this study. There were 136 such patients.

We performed an ambispective cohort study, where we retrospectively examined all patients who were initiated on ART since 2007 and prospectively examined the patients on two occasions with the SES tool, a median of 6 to 18 months post ART initiation. In addition to the SES status tool, demographic, clinical and ART adherence data (using a 7-day recall) were also collected [21].

The study was approved by the ethical review board, and data in the prospective study was collected after obtaining written informed consent.

Our objective was to evaluate the mean change in SES scores. Thus to detect a mean delta in SES scores of 2.5 pre and post ART, with $80 \%$ power and a 2 -sided alpha of 0.05 with a paired sample t-test, a sample size of 69 was required. We followed a cohort of 136 patients. The study period concluded in 2012.

Descriptive statistics were used to analyze the frequency data. The pre and post scores were compared using paired t-tests. Pearson's correlation coefficients 
were done as well. Univariate regression analysis was done to evaluate factors predictive of highest quartile increase in SES score. Those factors significant at 0.2 level or less were placed in multivariate analysis. All study data was transcribed in an Excel Database and analyzed by SAS (Version-9.1.3). All measures were taken to preserve the confidentiality of the participants.

\section{Results}

At the end of two years, 136 patients had continuous follow-up. The median follow up of both the retrospective and the prospective components of the cohort was 58 months. The demographic and clinical characteristics of the cohort are presented in Table 1.

There were 78 (57.4\%) females, median age was 38 years (range 38\% - 50\%); $93(68 \%)$ were married or living in, $25(18 \%)$ were widowed. Heterosexual sex was most common HIV risk among 99 (72.7\%), followed by IVDU (Intra-Venous Drug Use) and blood and blood products among 21 (15.4\%). Majority belonged to the Hindu religion 109 (80.2\%), while 24 (17.4\%) were Christian. The occupation of the patient was thus: professional/blue collar job $27(19.9 \%)$, skilled laborer $46(33.8 \%)$, daily wage laborer $12(8.8 \%)$, housewife 31 (22.8\%), others/unemployed/student 20 (14.7\%). Eighty one (59.5\%) had WHO stage III or IV at presentation, $45(33.3 \%)$ had an opportunistic infection at presentation, and 38 (28.2\%) had tuberculosis. The median baseline CD4 cell count was 165.8 cells/cumm. The median weight was $54.7 \mathrm{Kg}$ at baseline. Hundred and seven (78.7\%) were on Nevirapine based regimen, while 26 (19.1\%) were on Efavirenz based regimen, and $3(2.2 \%)$ were on protease inhibitor based regimen. A total of $128(96.9 \%)$ reported $100 \%$ adherence to ART in the prior week.

Figures 1-3 show the delta change in the socio-economic status (SES) scores as measured by the SES tool, from baseline to 6 months of follow up. In Figure 1 , from an increase by 27 points, 0 change, to a reduction of scores up to -9 points is noted. Figure 2 shows the distribution of the change in the total SES scores and the monthly income scores over the follow up period of 18 months. Figure 3 shows the percentage of participants who were in the different SES class pre ART and their distribution post-ART. As shown a substantial number went from the poor class to the middle and the rich class post ART initiation.

There was a significant change in the weight from mean baseline of $54.67 \mathrm{Kg}$ to follow up $58.47 \mathrm{Kg},(\mathrm{P}<0.0001)$; similarly the CD4 Cell count increase from a mean baseline of 165.7 cells/cumm to 497.9 cells/cumm at follow up was significant $(\mathrm{P}<0.0001)$. Moreover, these changes in weight and CD4 Cell count were positively correlated with the change in the SES scores. This is shown in Figure 2 and Figure 3. The delta change in weight is correlated with delta change in SES scores $(r=0.223, P=0.0048)$; and similarly the delta change in CD4 cell count is correlated to the delta change in the SES scores $(r=0.175, P=0.043)$.

We then performed logistic regression analysis to predict the factors associated with the highest quartile change in the SES Scores. Table 2 shows the univariate 
Table 1. Demographic and clinical characteristics of the cohort.

\begin{tabular}{|c|c|}
\hline Variable & N (\%) Median (Range) \\
\hline \multicolumn{2}{|l|}{ Gender } \\
\hline Female & $78(57.4 \%)$ \\
\hline Male & $58(42.6 \%)$ \\
\hline Age & $38(38 \%-50 \%)$ \\
\hline \multicolumn{2}{|l|}{ Marital Status } \\
\hline Married/Living in & $93(68.3 \%)$ \\
\hline Single & $10(7.3 \%)$ \\
\hline Divorced/Separated & $8(5.8 \%)$ \\
\hline Widowed & $25(18.3 \%)$ \\
\hline \multicolumn{2}{|l|}{ HIV Risk } \\
\hline Heterosexual sex & $99(72.7 \%)$ \\
\hline IVDU/Blood and Blood Products & $21(15.4 \%)$ \\
\hline Homosexual/Bisexual & $10(7.3 \%)$ \\
\hline Occupational & $6(4.4 \%)$ \\
\hline \multicolumn{2}{|l|}{ Religion } \\
\hline Hindu & $109(80.2 \%)$ \\
\hline Christian & $24(17.6 \%)$ \\
\hline Muslim/Others & $3(2.2 \%)$ \\
\hline \multicolumn{2}{|l|}{ Occupation of the Participant } \\
\hline Professional/Blue Collar Job & $27(19.9 \%)$ \\
\hline Skilled Laborer & $46(33.8 \%)$ \\
\hline Daily Wage Laborer & $12(8.8 \%)$ \\
\hline Housewife & $31(22.8 \%)$ \\
\hline Others/Unemployed/Student & $20(14.7 \%)$ \\
\hline Baseline WHO Classification Stage III or IV & $81(59.5 \%)$ \\
\hline Baseline Presence of any OI & $45(33.3 \%)$ \\
\hline Persons with Tuberculosis & $38(28.2 \%)$ \\
\hline Baseline CD4 cell Count (cells/cumm) & 165.8 \\
\hline Baseline Weight (Kg) & 54.7 \\
\hline \multicolumn{2}{|l|}{ Type of ART used } \\
\hline Nevirapine +2 nRTIs & $107(78.7 \%)$ \\
\hline Efavirenz +2 nRTIs & $26(19.1 \%)$ \\
\hline Protease Inhibitors +2 nRTIs & $3(2.2 \%)$ \\
\hline $100 \%$ Adherence to ART reported in Prior Week & $128(96.9 \%)$ \\
\hline
\end{tabular}




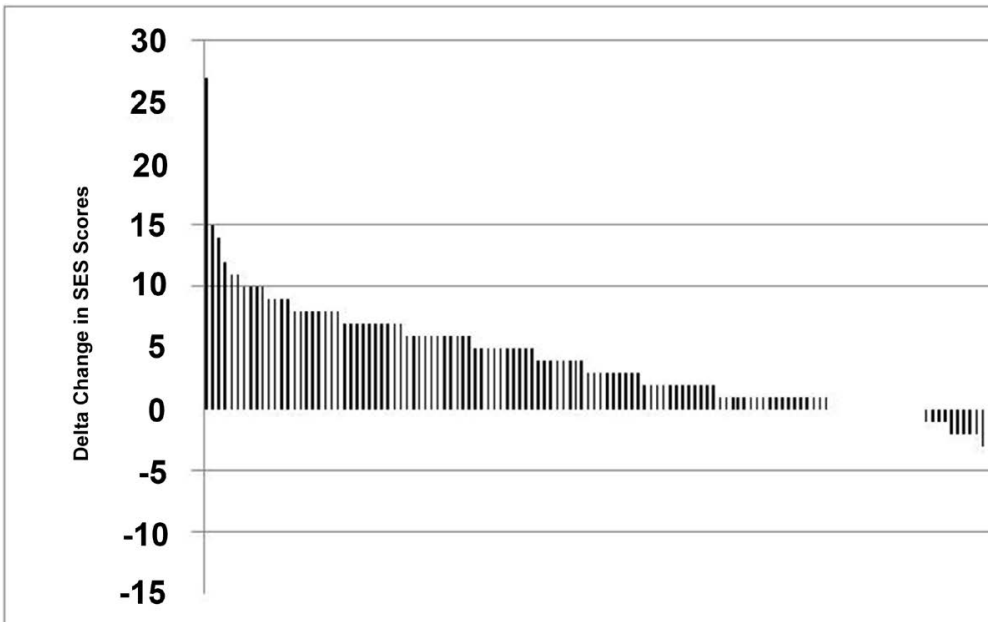

Figure 1. Distribution of the Delta-Change from Baseline to 6-month Follow up in the Socio-Economic Status (SES) Scores which shows arange of +27 points to -9 points at six months after ART initiation.

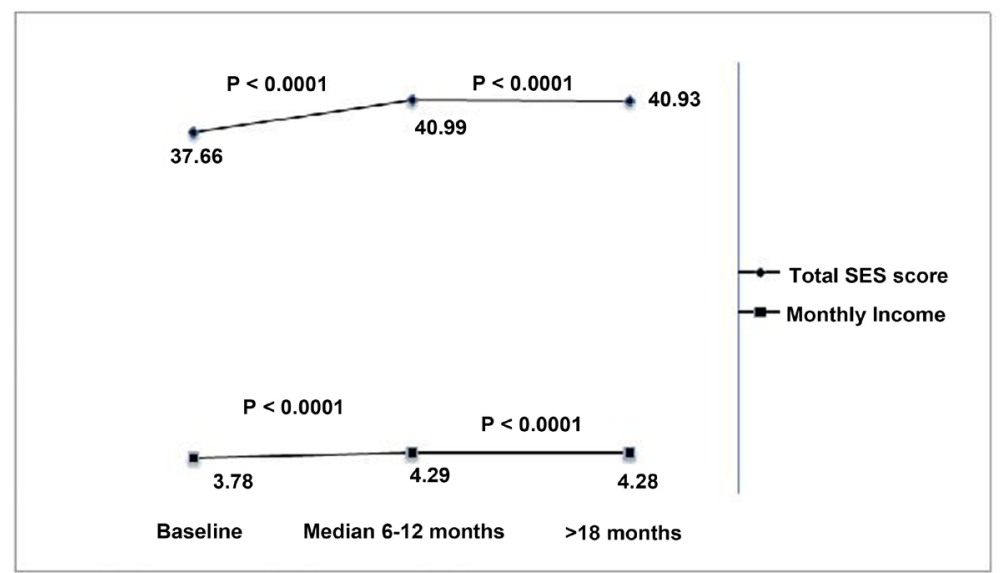

Figure 2. Distribution of change in total SES Score and Monthly income score across the study period.

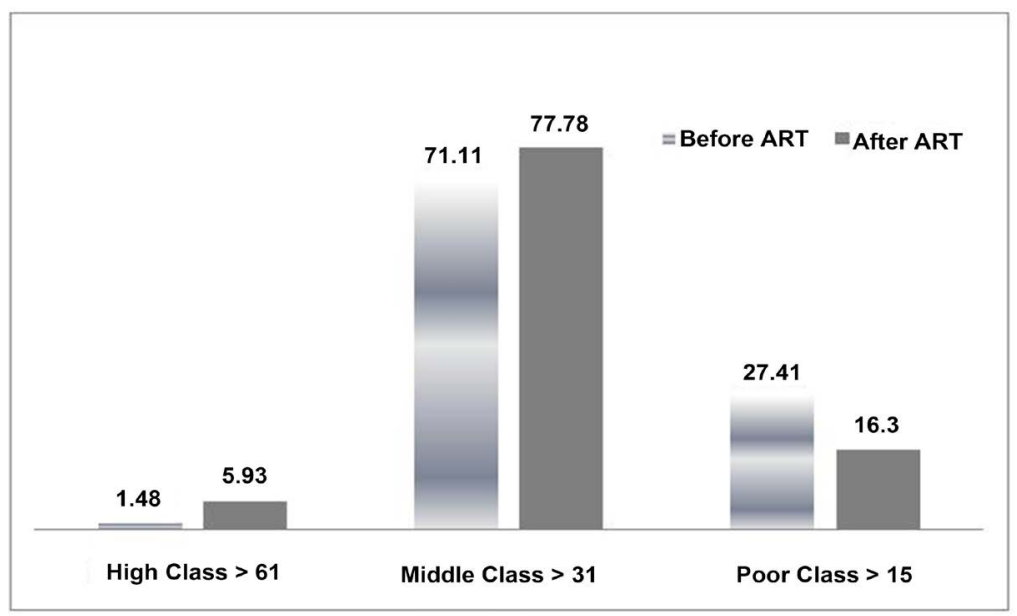

Figure 3. Distribution of change in Socio-Economic status (SES) productivity score Pre and post ART as stratified by the SES class. 
and multivariate logistic regression analysis results. The factors which were significant at 0.2 level or less were placed in the multivariate model. As shown, the following factors were significant at the 0.2 level or less on univariate analysis: the occupation of the participant being daily wage laborer (parameter estimate -0.8065 ; 95\% Odds Ratio: 0.45; Confidence Interval: $(0.11-1.79) \mathrm{P}=0.25)$; the occupation of the participant being a housewife $(-0.8755)$ OR:0.42; CI: $(0.14-$ 1.22); $\mathrm{P}=0.11$ ); Change in CD4+ Cell Count (Parameter Estimate: 0.0012; OR: 1.00; CI: (1.0 - 1.01); $\mathrm{P}=0.15)$; Change in weight (Parameter Estimate: 0.0647; OR: 1.07; CI: (1.0 - 1.14); $\mathrm{P}=0.04)$. On multivariate analysis, only being a housewife was significant (OR: 0.15; $95 \mathrm{CI}(0.022-0.946) ; \mathrm{P}=0.04)$.

\section{Discussion}

Among studies conducted in India, although one prior study has shown the improvement in socio-economic status with the use of ART, as measured by time worked and change in income levels, this to our knowledge is the first study which has assessed socio-economic impact of ART alone, using a well-validated tool, which assesses not only the monthly income, but also the fixed and movable assets, in a comprehensive manner over a prolonged post-ART follow up period [19].

The tool used to assess the Socio-Economic Status in our study, has been validated from a cross-sectional study of 2095 Indian families from, urban, rural, resettlement colony, slum and mobile settings. The tool has a total of 22 questions, which assess monthly household income; educational status of parents and children and societal and professional positions held; occupation and number of all earning members in the household; the kind of dwelling; number of children; family possessions, i.e. urban, agricultural or non-agricultural land and animal stock; type and locality of residence; income tax paid; caste; deployment of domestic help among other things. Moreover, this instrument is valid for all sections of the society, regardless of rural or urban setting [19].

Our data show significant positive correlation in the improvement in clinical parameters such as weight gain and CD4+ cell count increase and the change in SES status, which was also significant on the univariate analysis as a predictor for highest quartile change in the SES scores. This to our knowledge has not been well-documented in the literature. Even though change in income status have been looked at in conjunction with change in BMI, improvement in anemia, and CD4 cell counts, there have not been definite correlations drawn as has been demonstrated in this study [20].

The fact that the "monthly per capita income" improved significantly suggests increased employability, regardless of sale or acquisition of other fixed assets. Hence, not surprisingly, being a housewife was independently associated with the least change in the SES scores. Similar findings, where the impact of ART was much higher in men were reported by Thirumurthy et al., due to the baseline status as housewives of the women [21].

Better ART adherence has been associated with improved health utilization 
Table 2. Univariate and multivariate regression analysis of factors predicting the highest quartile change in the SES Score at 6 months post ART initiation as compared to Pre-ART scores.

\begin{tabular}{|c|c|c|c|c|c|}
\hline \multirow[t]{2}{*}{ Variable } & \multicolumn{3}{|c|}{ Univariate Analysis } & \multicolumn{2}{|c|}{ Multivariate Analysis } \\
\hline & $\begin{array}{c}\text { Parameter } \\
\text { Estimate (SE) }\end{array}$ & $\begin{array}{c}\text { Odds Ratio } \\
\text { (95\% Confidence Interval) }\end{array}$ & P Value & $\begin{array}{c}\text { Odds Ratio } \\
\text { (95\% Confidence Interval) }\end{array}$ & P Value \\
\hline $\begin{array}{c}\text { Daily Wage Laborer } \\
\text { (Participant Occupation) }\end{array}$ & -0.8065 & $0.45(0.11-1.79)$ & 0.25 & $0.39(0.065-2.376)$ & 0.31 \\
\hline $\begin{array}{c}\text { Being Housewife } \\
\text { (Participant Occupation) }\end{array}$ & -0.8755 & $0.42(0.14-1.22)$ & 0.11 & $0.15(0.022-0.946)$ & 0.04 \\
\hline Change in Weight in Kgs & 0.0647 & $1.07(1.00-1.14)$ & 0.04 & $1.06(0.988-1.146)$ & 0.10 \\
\hline Change in CD4+ Cell Count & 0.0012 & $1.00(1.00-1.01)$ & 0.15 & $1.00(0.99-1.003)$ & 0.39 \\
\hline
\end{tabular}

costs [22]. We report an ART adherence level of 100\% among more than $95 \%$ of our cohort. It is not possible to discern from our data if the ART adherence was a cause or the effect of the improved socio-economic productivity among PLHIV. Based on the fact, that even though about $20 \%$ of our participants did not have a significant improvement in their SES scores, yet had a near perfect ART adherence, suggests that the improved adherence is the cause of the SES productivity.

One limitation of this study was the sample size of 136 patients which appears small but was double what we required as per our calculations to determine outcome.

The ART access in India has been scaled significantly since 2004, when it was first publicly launched in 2004 [23]. There are more than 500 ART centers and approximately 1.1 million people have received free ART. Despite these efforts, ART coverage has stood at $\sim 50 \%$ based on the 2013 WHO ART eligibility guidelines largely because of the stigma and discrimination surrounding HIV/AIDS [23]. We believe that data such as ours which shed light on the economic impact of ART will be useful for economic modeling. Our data, show that, the use of ART is associated with significant improvement in the overall household incomes of PLHIV regardless of the costs incurred for HIV care. Our data is consistent with other studies from Africa which show a significant improvement of SES, and thus the overall improvement in quality of life with the use of ART, which can be used to increase the overall uptake of ART and its adherence in the developing countries [24]. Thus overall these results have significant policy implications in scaling up of ART in the national and global perspective especially when we can bring this bend to fight the stigma and discrimination for ART take up.

\section{Acknowledgements}

We thank all the patients of ASHA Foundation who took part in this study. The work related to the study-consent and interaction with patients, data collection and analysis was all conducted at ASHA Foundation, Bangalore. ASHA Foundation would also like to thank Kindernothilfe, Germany for supporting this study. 


\section{Conflicts of Interest}

The authors declare no conflicts of interest regarding the publication of this paper.

\section{References}

[1] (2017) UNAIDS Global Report. http://www.unaids.org/en/resources/campaigns/globalAIDSupdate2017

[2] Greener, R. (1998) Why Companies Should Intervene: A Case Study of the Costs of HIV/AIDS to Employers. Economic Impact: Southern Africa. AIDS Analysis Africa, 8, 3-4.

[3] Greener, R. (2002) AIDS and Macroeconomic Impact. In: Forsyth, S., Ed., State of the Art: AIDS and Economics, IAEN, 49-55.

[4] Hanson, K. (1992) AIDS: What Does Economics Have to Offer? Health Policy and Planning, 7, 315-328. https://doi.org/10.1093/heapol/7.4.315

[5] Morris, C.N. and Cheevers, E.J. (2000) The Direct Costs of HIV/AIDS in a South African Sugar Mill. AIDS Analysis Africa, 10, 7-8.

[6] Over, M. (1992) The Macroeconomic Impact of AIDS in Sub-Saharan Africa. Population and Human Resources Department, The World Bank, 1-39.

[7] Over, M., Revenga, A., Masaki, E., Peerapatanapokin, W., Gold, J., Tangcharoensathien, V. and Thanprasertsuk, S. (2007) The Economics of Effective AIDS Treatment in Thailand. AIDS, 21, S105-S116. https://doi.org/10.1097/01.aids.0000279713.39675.1c

[8] Economic Impact of HIV. http://en.wikipedia.org/wiki/AIDS

[9] National AIDS Control Organisation (NACO) (2006). www.nacoonline.org

[10] Beard, J., Feeley, F. and Rosen, S. (2009) Economic and Quality of Life Outcomes of Antiretroviral Therapy for HIV/AIDS in Developing Countries: A Systematic Literature Review. AIDS Care, 21 1343-1356. https://doi.org/10.1080/09540120902889926

[11] Bender, M.A., Kumarasamy, N., Mayer, K.H., Wang, B., Walensky, R.P., Flanigan, T., Freedberg, K.A., et al. (2010) Cost-Effectiveness of Tenofovir as First-Line Antiretroviral Therapy in India. Clinical Infectious Diseases. An Official Publication of the Infectious Diseases Society of America, 50, 416-425.

https://doi.org/10.1086/649884

[12] Palella Jr., F.J., Delaney, K.M., Moorman, A.C., Loveless, M.O., Fuhrer, J., Satten, G.A. and Holmberg, S.D. (1998) Declining Morbidity and Mortality among Patients with Advanced Human Immunodeficiency Virus Infection. HIV Outpatient Study Investigators. The New England Journal of Medicine, 338, 853-860. https://doi.org/10.1056/NEJM199803263381301

[13] Sendi, P., Palmer, A.J., Gafni, A. and Battegay, M. (2001) Highly Active Antiretroviral Therapy: Pharmacoeconomic Issues in the Management of HIV Infection. Pharmacoeconomics, 19, 709-713. https://doi.org/10.2165/00019053-200119070-00001

[14] Bozzette, S.A., Joyce, G., McCaffrey, D.F., Leibowitz, A.A., Morton, S.C., Berry, S.H., Goldman, D.P., et al. (2001) Expenditures for the Care of HIV-Infected Patients in the Era of Highly Active Antiretroviral Therapy. The New England Journal of Medicine, 344, 817-823. https://doi.org/10.1056/NEJM200103153441107

[15] Bendavid, E., Wood, R., Katzenstein, D.A., Bayoumi, A.M. and Owens, D.K. (1999) 
Expanding Antiretroviral Options in Resource-Limited Settings-A Cost-Effectiveness Analysis. Journal of Acquired Immune Deficiency Syndromes, 52, 106-113. https://doi.org/10.1097/QAI.0b013e3181a4f9c4

[16] Freedberg, K.A., Kumarasamy, N., Losina, E., Cecelia, A.J., Scott, C.A., Divi, N., Walensky, R.P., et al. (2007) Clinical Impact and Cost-Effectiveness of Antiretroviral Therapy in India: Starting Criteria and Second-Line Therapy. AIDS (London, England), 21, S117-S128. https://doi.org/10.1097/01.aids.0000279714.60935.a2

[17] Valenti, W.M. (2001) HAART Is Cost-Effective and Improves Outcomes. The AIDS Reader, 11, 260-262.

[18] Solomon, S., Batavia, A., Venkatesh, K.K., Brown, L., Verma, P., Cecelia, A.J., Mayer, K.H., et al. (2009) A Longitudinal Quality-of-Life Study of HIV-Infected Persons in South India: The Case for Comprehensive Clinical Care and Support Services. AIDS Education and Prevention: Official Publication of the International Society for AIDS Education, 21, 104-112.

https://doi.org/10.1521/aeap.2009.21.2.104

[19] Aggarwal, O.P., Bhasin, S.K., Sharma, A.K., Chhabra, P., Aggarwal, K. and Rajoura, O.P. (2005) A New Instrument (Scale) for Measuring the Socioeconomic Status of a Family: Preliminary Study. Indian Journal of Community Medicine, 30, 305-310.

[20] Orlando, S., Alumando, E.S., Marazzi, M.C., Germano, P., Guidotti, G., Gennaro, E., Ciccacci, F. and Palombi, L. (2012) The Impact of Anti-Retorviral Therapy on the Social, Economic and Working Conditions of Patients with HIV/AIDS in Malawi. XIX International AIDS Conference, Washington DC, 22-27 July 2012, E1-E66.

[21] Thirumurthy, H., Jafri, A., Srinivas, G., Arumugam, V., Saravanan, R.M., Angappan, S.K., Kallolikar, S., et al. (2011) Two-Year Impacts on Employment and Income among Adults Receiving Antiretroviral Therapy in Tamil Nadu, India: A Cohort Study. AIDS (London, England), 25, 239-246. https://doi.org/10.1097/QAD.0b013e328341b928

[22] Nachega, J.B., Leisegang, R., Bishai, D., Nguyen, H., Hislop, M., Cleary, S. and Maartens, G. (2010) Association of Antiretroviral Therapy Adherence and Health Care Costs. Annals of Internal Medicine, 152, 18-25. https://doi.org/10.7326/0003-4819-152-1-201001050-00006

[23] National AIDS Control Organisation (NACO) (2010). http://www.nacoonline.org

[24] Thirumurthy, H., Zivin, J.G. and Goldstein, M. (2008) The Economic Impact of AIDS Treatment: Labor Supply in Western Kenya. The Journal of Human Resources, 43, 511-552. https://doi.org/10.3368/jhr.43.3.511 